\title{
El lápiz como arma: la respuesta del humor gráfico al atentado terrorista contra Charlie Hebdo
}

\author{
Israel V. Márquez \\ Universidad Complutense de Madrid. \\ Departamento de Periodismo y Nuevos Medios \\ isravmarquez@ucm.es
}

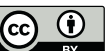

Fecha de presentación: marzo de 2020

Fecha de aceptación: febrero de 2021

Fecha de publicación: diciembre de 2021

Cita recomendada: MÁRQUEZ, I. V. (2021). «El lápiz como arma: la respuesta del humor gráfico al atentado terrorista contra Charlie Hebdo». Anàlisi: Quaderns de Comunicació $i$ Cultura, 65, 137-154. DOI: <https://doi.org/10.5565/rev/analisi.3302>

\section{Resumen}

El presente artículo analiza la respuesta del humor gráfico al atentado terrorista del 7 de enero de 2015 contra las oficinas del semanario satírico francés Charlie Hebdo. En concreto, el artículo realiza un análisis semiótico de una serie de piezas relacionadas con este suceso y recopiladas a través de Internet. Los textos visuales y verbovisuales analizados evidencian la condena del ataque terrorista y la defensa de la libertad de expresión, representada en la mayoría de casos por la imagen del lápiz como herramienta de lucha contra el terrorismo y símbolo de los valores democráticos.

Palabras clave: humor gráfico; semiótica; metáfora; periodismo; democracia

Resum. El llapis com a arma: la resposta de l'humor gràfic a l'atemptat terrorista contra Charlie Hebdo

Aquest article analitza la resposta de l'humor gràfic a l'atemptat terrorista del 7 de gener de 2015 contra les oficines del setmanari satíric francès Charlie Hebdo. En concret, l'article fa una anàlisi semiòtica d'un seguit de peces relacionades amb aquest succés que han estat recopilades a través d'internet. Els textos visuals i verbovisuals analitzats evidencien la condemna de l'atac terrorista i la defensa de la llibertat d'expressió, representada en la majoria de casos per la imatge del llapis com a eina de lluita contra el terrorisme i símbol dels valors democràtics.

Paraules clau: humor gràfic; semiòtica; metàfora; periodisme; democràcia 
Abstract. The Pencil as Weapon: The Graphic Humour response to the Charlie Hebdo Terrorist Attack

This paper analyses the graphic humour response to the Charlie Hebdo terrorist attack on January 7, 2015. The paper carries out a semiotic analysis of a series of pieces related to this event collected via the internet. The visual and verbo-visual texts analysed demonstrate condemnation of the terrorist attack and defence of freedom of expression, mostly represented by the image of the pencil as a weapon against terrorism and a symbol of democratic values.

Keywords: graphic humour; semiotics; metaphor; journalism; democracy

\section{Introducción y estado de la cuestión}

A lo largo del siglo XXI, el semanario francés Charlie Hebdo se ha convertido en una de las publicaciones satíricas más polémicas y controvertidas del panorama internacional. La revista, tal y como hoy la conocemos, se fundó en el año 1992, tomando su nombre de una publicación satírica mensual que existió entre los ańos 1969 y 1981 bajo los nombres de Hara-Kiri, Hara-Kiri Hebdo, L'Hebdo Hara-Kiri y finalmente Charlie, en homenaje a Charlie Brown, personaje principal de la famosa serie de tiras cómicas Peanuts (también conocida como Snoopy, Charlie Brown o Carlitos). En el año 1981 se suspende la publicación de la revista debido a la falta de ingresos y de lectores, pero en 1992 renace en forma de semanario y bajo el nombre actual de Charlie Hebdo ('el semanario de Charlie').

Este semanario francés cobró relevancia internacional en el año 2006, a raíz de que sus responsables decidieran republicar unas caricaturas de Mahoma que aparecieron originalmente en el periódico danés Jyllands-Posten. Este hecho causó un enorme revuelo en la comunidad internacional y generó debates en torno a los límites entre el humor y la libertad de expresión. El semanario fue amenazado por sus sátiras y caricaturas sobre Mahoma y la religión islámica, y en el año 2011 sufrió un primer atentado a su sede con un cóctel Molotov. Cuatro años más tarde se produjo un segundo atentado que causó la muerte de varias personas, entre ellas Stéphane Charbonnier (Charb), el director de la publicación, el cual figuraba en la lista de los más buscados por $\mathrm{Al}$ Qaeda ${ }^{1}$, y los dibujantes Cabu, Tignous, Honoré y Georges Wolinski.

El atentado fue rápidamente condenado por parte de la comunidad política internacional y dio lugar a la celebración de varias manifestaciones ciudadanas que convirtieron el lema "Je suis Charlie» en un homenaje a las víctimas y un símbolo de la libertad de expresión. Entre las múltiples imágenes y textos que circularon después del atentado, los cuales han sido objeto de varios análisis académicos (Leone, 2015; Wolska-Zogata, 2015; Gustafson y

1. <http://www.telegraph.co.uk/news/worldnews/europe/france/11330505/MurderedCharlie-Hebdo-cartoonist-was-on-al-Qaeda-wanted-list.html>. 
Kenix, 2016; Gómez-Domínguez et al., 2017; Al Nashmi, 2018; Eko y Hellmueller, 2018; Giaxoglou, 2018; Payne, 2018; Jenkins y Tandoc, 2019; Niemeyer, 2019; Johansson y Laippala, 2020), encontramos también las imágenes elaboradas por los propios dibujantes en homenaje a sus compañeros de profesión muertos durante el atentado. Este corpus de imágenes no ha recibido demasiada atención académica ${ }^{2}$, a pesar de su importancia en un caso como este, el cual nos permite observar de primera mano cómo responden los dibujantes a un ataque directo contra su propio trabajo bajo la forma radical de un asesinato. El objetivo de este artículo es, por tanto, observar la respuesta de dibujantes y humoristas gráficos al atentado terrorista contra Charlie Hebdo a partir del análisis de algunas imágenes sobre este acontecimiento recopiladas a través de Internet.

\section{Metodología}

La metodología utilizada en este artículo es el análisis semiótico, entendido como «un conjunto de conceptos y operaciones destinado a explicar cómo y por qué un determinado fenómeno adquiere, en una determinada sociedad, y en un determinado momento histórico de tal sociedad, una determinada significación» (Magarińos de Morentín, 2008: 23). En concreto, realizaremos un análisis semiótico de textos visuales (Abril, 2008) dirigido a interpretar cómo los elementos visuales - o visuales y verbales - de las viñetas y tiras del humor gráfico se combinan entre sí para producir efectos de sentido. Este tipo de estudio parte del análisis semiótico del discurso propio del «paradigma lingüístico» para adaptarlo al "giro de la imagen» o "giro pictórico» (pictorial turn) evidenciado por Mitchell (1994), entendiendo los textos visuales o verbovisuales como objetos de estudio por derecho propio.

Las imágenes analizadas han sido seleccionadas a través de Internet, mediante la plataforma digital The Cartoon Movement, la cual reúne actualmente el trabajo de numerosos dibujantes y humoristas gráficos de diferentes partes del mundo, y a través de galerías de imágenes disponibles en otros espacios de la red (blogs, redes sociales, plataformas de intercambio de imágenes, etc.). Dada la imposibilidad de analizar todas las imágenes de humoristas gráficos generadas en respuesta a este atentando en un trabajo de estas características, hemos seleccionado únicamente algunas de las más significativas, siguiendo con ello la advertencia de Rose (2001) de que la semiótica no se preocupa por encontrar imágenes estadísticamente representativas de un conjunto más amplio de imágenes (tal y como ocurre, por ejemplo, con el análisis de contenido), sino imágenes que sean conceptualmente interesantes y que permitan realizar un análisis más profundo y detallado. Sin embargo, podemos concluir que la respuesta general por parte de la gran mayoría de dibujantes fue la condena del ataque terrorista y la defensa de la libertad de expre-

2. Tres notables excepciones son los trabajos de Domínguez (2015), Bouko, Calabrese y De Clercq (2016) y Bezanson (2017). 
sión, representada en la mayoría de casos, como se verá, en la imagen del lápiz como herramienta de lucha y resistencia contra el terrorismo y símbolo de los valores democráticos.

Por último, conviene hacer algunas observaciones sobre el estudio del humor gráfico en la era digital actual. Internet ha facilitado enormemente la difusión y la visibilidad del humor gráfico a un nivel global, lo que nos ha permitido acceder instantáneamente a viñetas y a tiras cómicas de diferentes partes del mundo, algo que tradicionalmente no ha resultado tan sencillo debido a las propias limitaciones del formato de papel. También ha creado espacios en los que los propios dibujantes pueden compartir y dar a conocer sus trabajos, así como juzgar y evaluar el trabajo de otros, tal y como sucede en la plataforma y comunidad virtual The Cartoon Movement. Por todo ello, el humor gráfico actual no puede entenderse sin tener en cuenta este tipo de transformaciones digitales que han facilitado a los lectores, por un lado, el poder acceder rápidamente a piezas de humor gráfico de diferentes lugares, y a los propios dibujantes, por otro, el poder exponer su trabajo ante otros dibujantes y colegas. Para el académico, todo esto ha supuesto también una enorme ventaja, ya que Internet permite entrar rápidamente en piezas internacionales de humor gráfico y no limitarse a las viñetas y tiras de diarios y revistas locales, como ha sido lo habitual en este tipo de estudios. Consideramos, pues, que cualquier análisis actual del humor gráfico no puede dejar de lado su actual presencia y difusión en Internet, ya sea en plataformas como The Cartoon Movement, en las propias versiones digitales de periódicos y revistas o en otros espacios de la red como blogs y redes sociales.

\section{Sobre el humor gráfico}

Antes de centrarnos en el caso que nos ocupa, conviene hacer algunas observaciones sobre el humor gráfico y su peculiaridad como medio de comunicación de masas. A pesar de ser un componente fundamental de la prensa diaria, el humor gráfico sigue sin despertar un excesivo interés académico si lo comparamos con otro tipo de discursos periodísticos como los escritos, los radiofónicos o los audiovisuales. El humor gráfico nos hace observar la realidad y la actualidad informativa de otra manera, a través de un lenguaje peculiar que se distingue claramente de otros textos informativos cotidianos por su imaginativa combinación de signos visuales y verbales y por su énfasis en el juego y el humor como formas de criticar y hacer reflexionar sobre algún hecho o noticia.

El peculiar lenguaje verbovisual del humor gráfico, señala Peñamarín (1996: 111), «tiene la primera y esencial función de abrir un marco comunicativo especial, autorizado para el juego y el humor", un marco en el que cabe «una gama ilimitada de posicionamientos y laminaciones, desde los chistes propiamente tales [...] hasta los actos comunicativos más serios, como protestas, análisis, propuestas, homenajes, etc.». El humor gráfico genera asocia- 
ciones creativas e inesperadas entre hechos, personas y cosas, combinando signos verbales y visuales (o únicamente visuales, en algunos casos) que se unen y se mezclan entre sí en un mismo plano compositivo, si nos encontramos ante una vińeta, o a través de una ingeniosa secuencia narrativa, si nos hallamos frente a una tira cómica.

Pero el humor gráfico va más allá de este placer estético y semiótico derivado de sus ingeniosas combinaciones de imágenes y palabras para hacer un cuestionamiento lúdico, crítico o satírico de la actualidad dirigido al intelecto de los lectores. En este sentido, las imágenes críticas del humor gráfico, como señala Álvarez Junco (2016: 119), «son observadas y disfrutadas por un público necesitado de su propuesta" y que, gracias a ellas, se burla y reflexiona colectivamente «ante las excesivas formalizaciones y falsedades que tratan de imponerse». El humor gráfico, concluye este autor, ofrece al ciudadano «algo fundamental desde el punto de vista espiritual: una lúdica y distanciada reflexión de la realidad», una reflexión hecha de imágenes y palabras que divierten y liberan al tiempo que hacen pensar.

\section{Contextualizando el atentado del 7 de enero}

El 7 de enero de 2015, dos hombres encapuchados y armados asaltan las oficinas del semanario satírico francés Charlie Hebdo en París y provocan la muerte de doce personas, entre ellos los dibujantes Charb, Cabu, Tignous, Georges Wolinsky y Honoré. El atentado fue reivindicado por Al Qaeda en la Península Arábiga, una organización terrorista yihadista afiliada a Al Qaeda que opera principalmente en Yemen y Arabia Saudita. El mismo día del ataque, el Gobierno francés elevó al máximo el nivel de alerta terrorista y los dos autores del atentado, los hermanos Saïd y Chérif Kouachi, fueron encontrados y abatidos dos días después en la localidad francesa de Dammartin-enGoële.

El atentado fue rápidamente condenado por diversos líderes de la comunidad internacional y generó diversas manifestaciones de rechazo en Francia y otros países. Así mismo, en los momentos que siguieron al atentado, se difundió el lema "Je suis Charlie» ('Yo soy Charlie') a través de Internet y las redes sociales, el cual se convirtió en uno de los eslóganes más populares y más utilizados en la historia de Twitter. Como ha señalado Leone (2015), el «Je» ('Yo') del «Je suis Charlie» funcionó rápidamente como un signo de empatía hacia aquellos que habían sido brutalmente asesinados y como una expresión de proximidad humana que permitía a cada cual apropiarse de ese "Yo", habitar el tiempo de su enunciación y transportar su contenido a cualquier latitud. Reproducciones literales de esta frase y variantes de la misma (como por ejemplo «Nous sommes Charlie», «Soy Charlie», «Somos Charlie», etc.) fueron utilizadas durante las manifestaciones en apoyo y homenaje a las víctimas, tanto en Francia como en otros países. Igualmente, la frase y sus variantes fueron utilizadas por varios usuarios de redes sociales, como avatar personal o imagen de perfil. La propia web de Charlie Hebdo, que colapsó 
minutos después del atentado, fue restaurada con la frase "Je suis Charlie» sobre un fondo negro, y el motor de búsqueda Google ubicó durante unos días una pequeña imagen con la expresión "Je suis Charlie» y un fondo negro en su página principal.

Sin embargo, el discurso solidario masivo representado por la frase "Je suis Charlie» fue rápidamente cuestionado por un discurso de signo contrario que, bajo expresiones como "Je ne suis Pas Charlie» o "Je suis Ahmed» (en relación al policía musulmán muerto durante la huida de los terroristas), cuestionaba que el eslogan "Je suis Charlie» fuera en realidad un símbolo de Francia y una encarnación de los valores occidentales o europeos, sino más bien una defensa de la democracia y la libertad de expresión condicionada por razones políticas e ideológicas, ya que la mayoría de las víctimas de otros actos terroristas son completamente ignoradas (Petrof, 2015), tal como recordaba Boaventura de Sousa Santos en su artículo "Charlie Hebdo: Una reflexión difícil»:

La repugnancia total e incondicional que los europeos sienten ante estas muertes debe hacernos pensar por qué razón no sienten la misma repulsa ante un número igual o mucho mayor de muertes inocentes como resultado de conflictos que, en el fondo, ¿tal vez tengan algo que ver con la tragedia de Charlie Hebdo? En el mismo día, 37 jóvenes fueron muertos en Yemen en un atentado con bomba. El verano pasado, la invasión israelita causó la muerte de dos mil palestinos, de los cuales cerca de 1.500 eran civiles y 500 niños. En México, desde el año 2000 fueron asesinados 102 periodistas por defender la libertad de expresión y, en noviembre de 2014, 43 jóvenes fueron asesinados en Ayotzinapa.

Ciertamente que la diferencia en la reacción no puede estar basada en la idea de que la vida de europeos blancos, de cultura cristiana, vale más que la vida de europeos de otros colores o de no europeos de culturas basadas en otras religiones o regiones. ¿¿Será entonces porque estos últimos están más lejos de los europeos y estos los conocen menos? ¿Acaso el mandato cristiano de amar al prójimo permite tales distinciones? ¿Será porque los grandes media y los líderes políticos de Occidente trivializan el sufrimiento causado a esos otros, cuando no los demonizan al punto de hacernos pensar que ellos no merecen otra cosa? (De Sousa Santos, 2015)

El atentado del 7 de enero está directamente relacionado con la propia línea editorial de la publicación, atea y de izquierdas. Sus contenidos se caracterizan por la crítica social y política a través de viñetas, reportajes y chistes, mediante los cuales han atacado duramente a la extrema derecha, el catolicismo, el judaísmo o el islamismo. En el caso concreto del islam, a partir de febrero de 2006 Charlie Hebdo se convierte en el centro de una importante controversia política en torno a los límites entre humor y libertad de expresión, al publicar una serie de caricaturas de Mahoma aparecidas originalmente en el semanario danés Jyllands-Posten y añadir algunas otras. A raíz de ello, el semanario decide publicar un manifiesto firmado por doce intelectuales y 
difundido en otros medios de comunicación en el que se defendía la libertad de expresión a través de la caricatura y el humor gráfico y se advertía sobre los peligros del nuevo "totalitarismo» islámico, al que definían como «una ideología reaccionaria que mata la igualdad, la libertad y el secularismo dondequiera que esté presente» ${ }^{3}$.

En marzo de 2007 el Tribunal Correccional de París absolvió a la publicación de una demanda interpuesta por dos organizaciones islámicas (La Gran Mezquita de París y la Unión de Organizaciones Islámicas de Francia) considerando que la publicación de las caricaturas estaba amparada por el derecho a la libertad de expresión y no eran constitutivas del delito de injurias. El semanario, sin embargo, se convirtió en objetivo de amenazas por parte de islamistas radicales y en noviembre de 2011 sufrió un primer ataque a su sede y un jaqueo a su página web relacionados con la publicación de un polémico número especial en cuya portada se mostraba una caricatura de Mahoma (nombrado «redactor jefe» del número) acompañado de la frase «100 latigazos si no te mueres de la risa». El ataque no afectó a la línea crítica y reivindicativa de la revista, y en septiembre de 2012 el medio publicó una nueva serie de caricaturas satíricas sobre Mahoma, incluyendo algunas en las que aparecía desnudo, lo que provocó que el Gobierno francés cerrara embajadas, consulados, centros culturales y escuelas francesas en unos veinte países árabes, y que la policía antidisturbios tuviera que rodear la sede del semanario para protegerla contra posibles ataques.

\section{El lápiz como respuesta}

Centrándonos ya en el objetivo principal de este trabajo, el análisis de la respuesta del humor gráfico al atentado terrorista contra Charlie Hebdo, lo que más nos llamó la atención de las imágenes generadas a raíz de este acontecimiento fue la reiteración de la imagen del lápiz como herramienta de combate en la lucha contra el terrorismo y símbolo de la libertad de expresión. Muchos dibujantes encontraron en la representación visual del lápiz - el instrumento de escritura más típicamente asociado con el trabajo de un dibujante (Bezanson, 2017) - y en objetos similares como pinceles o plumas, una manera creativa de defender su trabajo y de homenajear a los compañeros de profesión muertos durante el atentado. Veamos algunos ejemplos.

La imagen de la figura 1, obra del dibujante sueco Jan-Erik Ander (Jeander), se inspira en el conocido cuadro La libertad guiando al pueblo, de Eugène Delacroix, para rendir homenaje a las víctimas del atentado y condenar el ataque terrorista. Los cuadros famosos son parte de la iconografía popular de un país, y para los humoristas gráficos funcionan como una eficaz "herramienta contextualizadora» (Álvarez Junco, 2016) y «marco intertextual» (Abril, 2008) que simplifican al lector la situación descrita en la viñe-

3. <http://news.bbc.co.uk/2/hi/europe/4764730.stm>. 
ta y le ponen en situación de comprender el tema con prontitud. En este caso, la utilización del cuadro de Delacroix como marco cultural de referencia es muy acertado, ya que se trata de un emblemático cuadro francés conservado en el Museo del Louvre de París y un símbolo universal de la lucha por la libertad y los derechos humanos. En la viñeta, la bandera francesa que porta la figura alegórica de la Libertad en el cuadro original ha sido sustituida por un lápiz junto al cual observamos una bandera rasgada (como la de Francia en el cuadro original) en la que podemos leer la icónica frase "Je suis Charlie», popularizada momentos después del atentado, como ya hemos señalado. Así mismo, las armas que portan la Libertad y las figuras que representan a la burguesía y la clase obrera, unidos en la lucha por la libertad, han sido reemplazadas por lápices y pinceles como únicas «armas» con las que combatir el terrorismo y defender la libertad de expresión. El diálogo intertextual que establece la viñeta con el cuadro de Delacroix permite traer al momento actual el sentido de lucha por la libertad, presente en el cuadro original a través de una nueva configuración sintagmática que mezcla signos propios del cuadro de Delacroix con signos relacionados con el atentado contra Charlie Hebdo.

Figura 1. Liberté, de Jan-Erik Ander (Jeander)

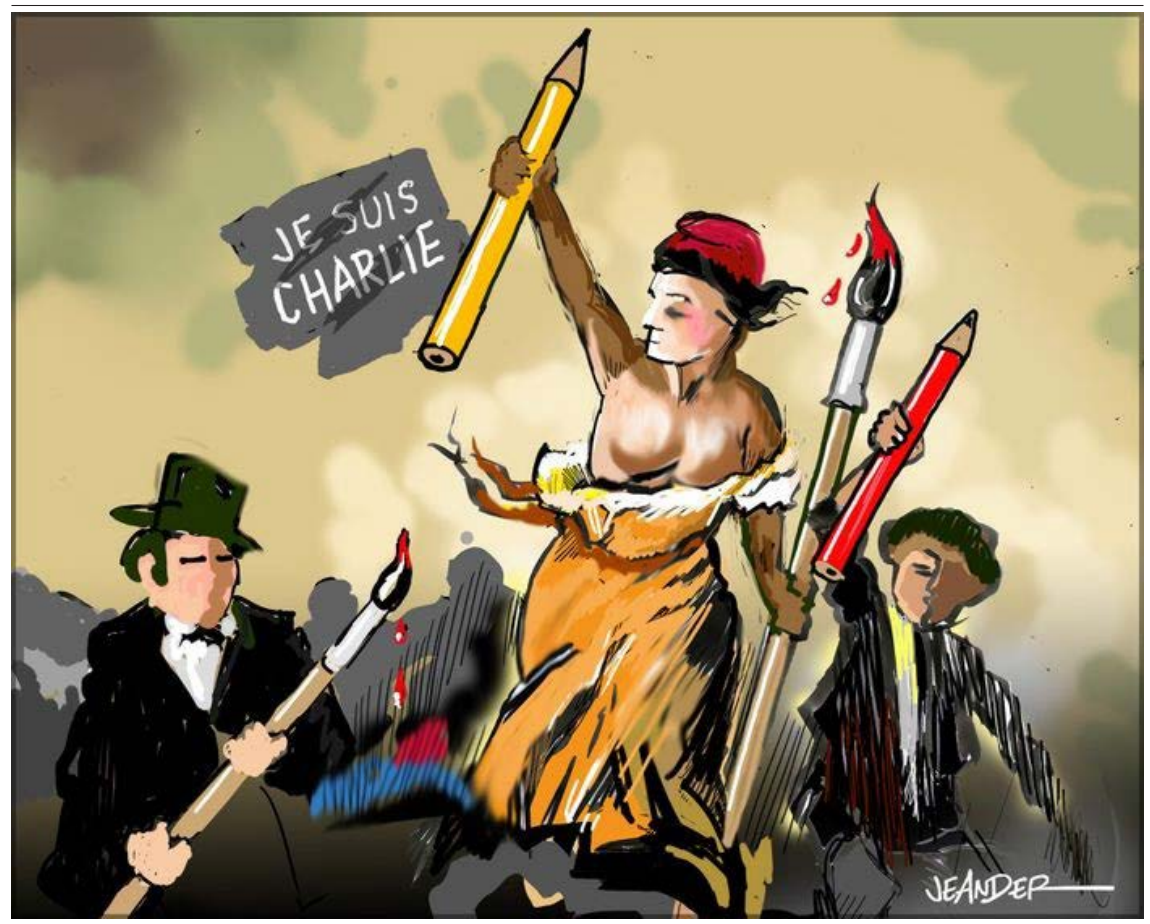

Fuente: <https://cartoonmovement.com/cartoon/liberte>. 
En la siguiente vińeta (figura 2), firmada por el artista y dibujante ruso Vladimir Khakhanov, el lápiz se convierte en una poderosa herramienta de combate a partir de la cual se consigue frenar las acciones violentas del terrorista. Los disparos que salen de su ametralladora chocan contra la línea curva dibujada por uno de los lápices, que actúa a modo de escudo o barrera, mientras los otros lápices dibujan simultáneamente trampas y obstáculos como cáscaras de plátano o un ladrillo que cae desde arriba y se dirige a la cabeza del terrorista. La viñeta pone de manifiesto el poder colectivo de los lápices, el dibujo y la imaginación para hacer frente a la amenaza terrorista y dificultar así sus movimientos y acciones.

Figura 2. The Pencil is Great Power, de Vladimir Khakhanov

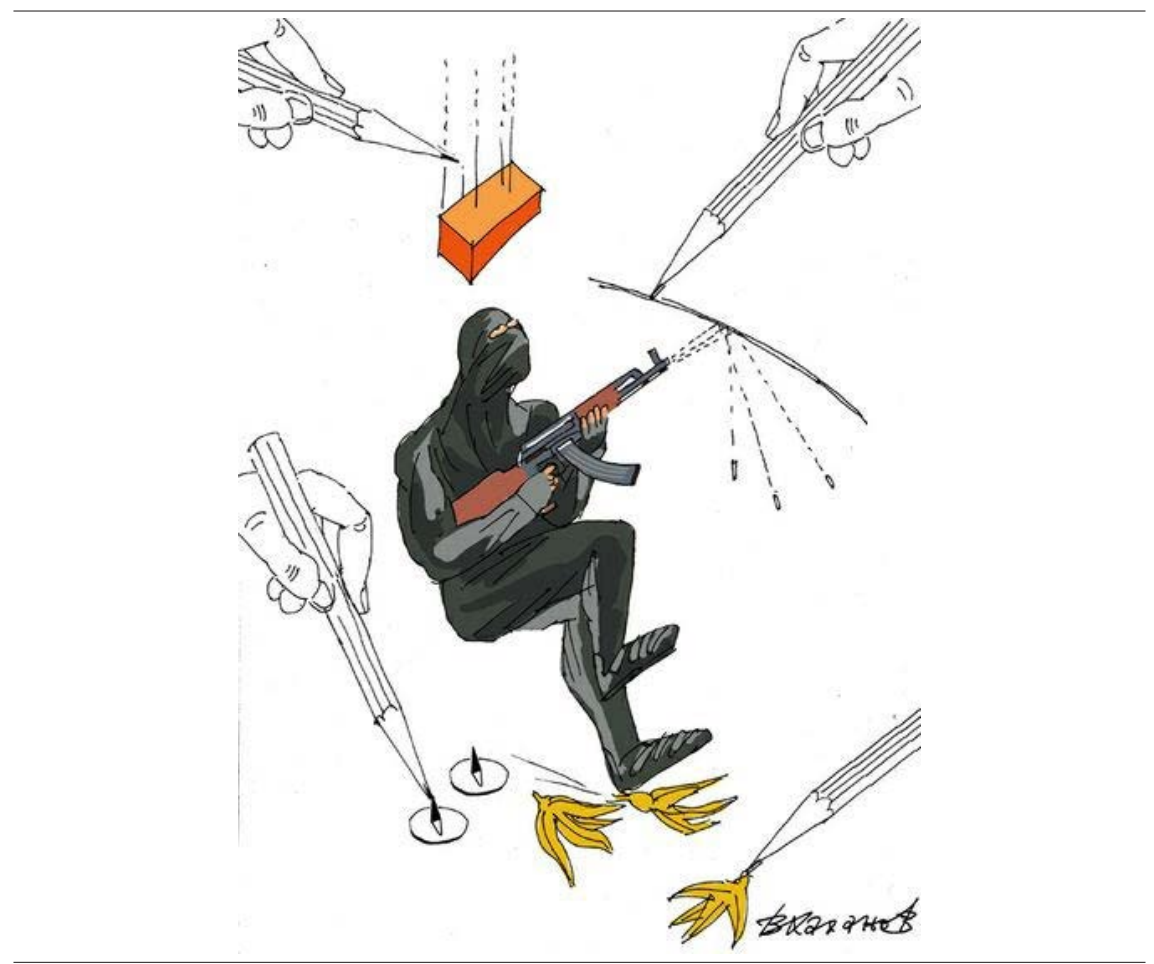

Fuente: <https://cartoonmovement.com/cartoon/pencil-great-power>.

En la siguiente viñeta (figura 3), obra del dibujante holandés Tjeerd Royaards, editor de la web The Cartoon Movement y cuyo trabajo ha sido publicado en medios como The Guardian, Der Spiegel o Le Monde, un terrorista encapuchado y armado con una escopeta es reducido a partir de una serie de líneas dibujadas con lápices de diferentes colores. El enfado del terrorista se expresa con sus ojos abiertos y las cejas fruncidas, y con la representación de la comisura de los labios hacia abajo y mostrando los 
dientes, signo que, según el código de expresividad facial desarrollado por los dibujantes de cómics y del humor gráfico, significa cólera (Gasca y Gubern, 1991: 127).

Las líneas dibujadas actúan como si fueran hilos o cuerdas que rodean y envuelven al terrorista y le dejan sin posibilidad de movimiento. Las imágenes reiteradas de las manos, los lápices y los trazos pueden entenderse como una forma de isotopia plástica, esto es, una especie «rima icónica» que construye una coherencia de tipo visual (Abril, 2008: 127)4. A través de todos estos elementos, la vińeta viene a simbolizar el poder colectivo de los lápices y el dibujo - de la creación artística en general- para combatir el terrorismo y contener y controlar su violencia (Bezanson, 2017), reduciendo al terrorista con la fuerza de los lápices, los trazos y los colores.

Figura 3. Keep Drawing!, de Tjeerd Royaards

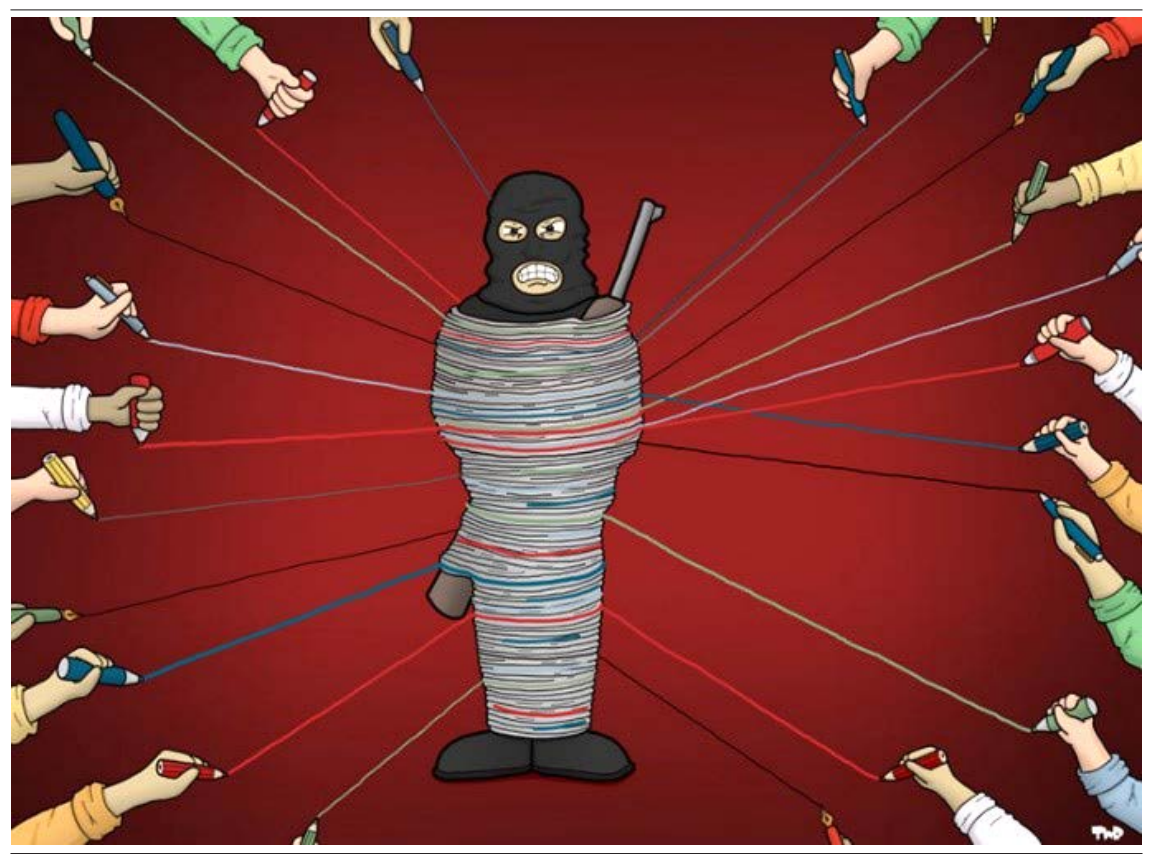

Fuente: <https://cartoonmovement.com/cartoon/keep-drawing >.

En esta otra imagen (figura 4), publicada por Gary Varvel en el diario estadounidense Indianapolis Star, vemos de nuevo un uso del lápiz como instrumento de combate, pero esta vez no a través de su punta y su uso como

4. En semiótica, la isotopía se refiere a «la permanencia recurrente a lo largo del discurso de un mismo haz de categorías justificativas de una organización paradigmática» (Greimas, 1976: 20), o lo que es lo mismo, a «la existencia de redundancia, de reiteración o de repetición de elementos similares o compatibles» (Lozano, Peña-Marín y Abril, 1982: 30). 
herramienta de dibujo y/o de escritura, sino a través de la goma de borrar incorporada que encontramos en muchos modelos de lápices. A partir de esta útil posibilidad de borrado, la mano que representa sinecdóquicamente al dibujante (y, por ende, a todos los dibujantes y las dibujantes que condenaron el atentado) borra la imagen del terrorista mientras este huye con una expresión de asombro dirigiendo su mirada a la mano y al lápiz (o, mejor dicho, al actante mano-lápiz), que van haciendo desaparecer su figura. Así mismo, el nombre del fabricante, que normalmente aparece escrito en el cuerpo del lápiz, ha sido sustituido por la palabra freedom ('libertad'), convirtiendo así a este utensilio básico para escritores y dibujantes en un símbolo de la lucha por la libertad.

Figura 4. Freedom, de Gary Varvel

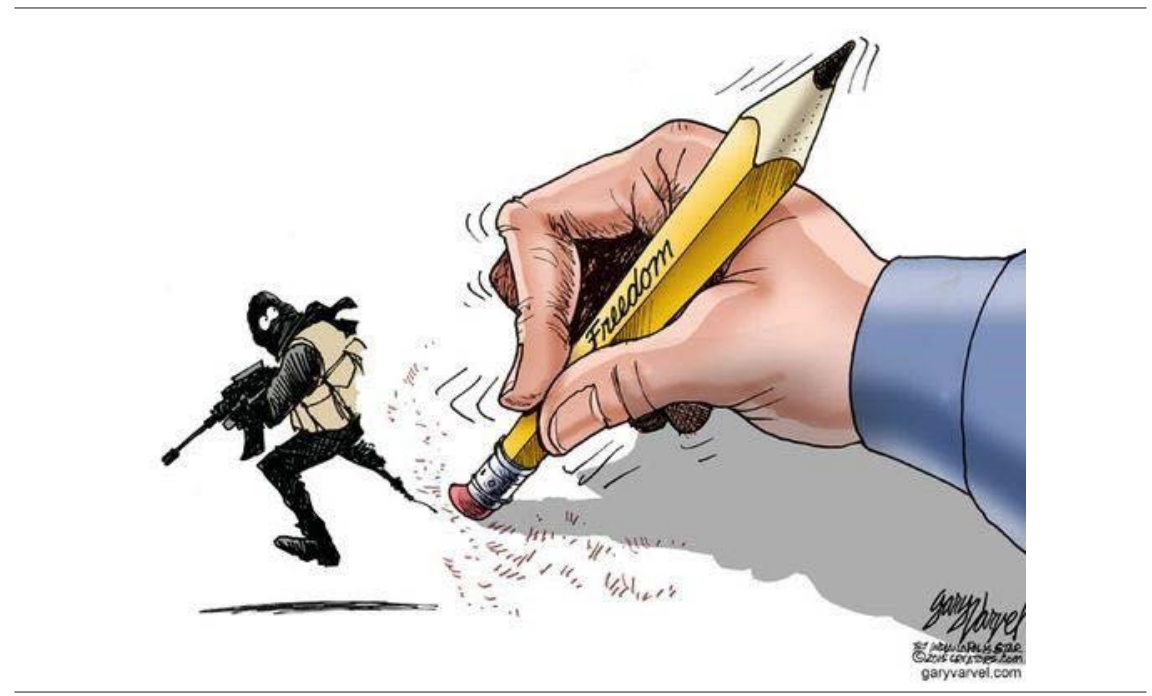

Fuente: <https://www.cartoonistgroup.com/properties/varvel/art_images/cg54af5658d4f70.jpg>.

La siguiente imagen (figura 5), obra del británico James Walmesley, desarrolla una idea similar, pero esta vez a partir del desarrollo secuencial propio de una tira cómica y no a través del bloque gráfico y espacio-temporal conjunto característico de una vińeta. En la imagen observamos un interesante desarrollo narrativo en el que un terrorista (metonimia del terrorismo en general) dispara contra un lápiz partiéndolo por la mitad, pero este es resucitado a través de un sacapuntas que le otorga una nueva vida y ataca al terrorista con su goma de borrar, haciéndole desaparecer. De nuevo, el lápiz es representado como símbolo de lucha y la metáfora del sacapuntas actúa como un modo de referirse a las múltiples vidas de un lápiz y, por tanto, a la imposibilidad de acabar con este, con el humor gráfico y con la libertad de expresión. El mensaje lingüístico «Je suis Charlie» situado debajo de la tira remite 
intertextualmente al famoso eslogan viralizado horas después del atentado, al tiempo que cumple una función de «anclaje» del mensaje icónico que contribuye a fijar o a reforzar el sentido de la imagen (Barthes, 1986).

Figura 5. Pencil and eraser, de James Walmesley
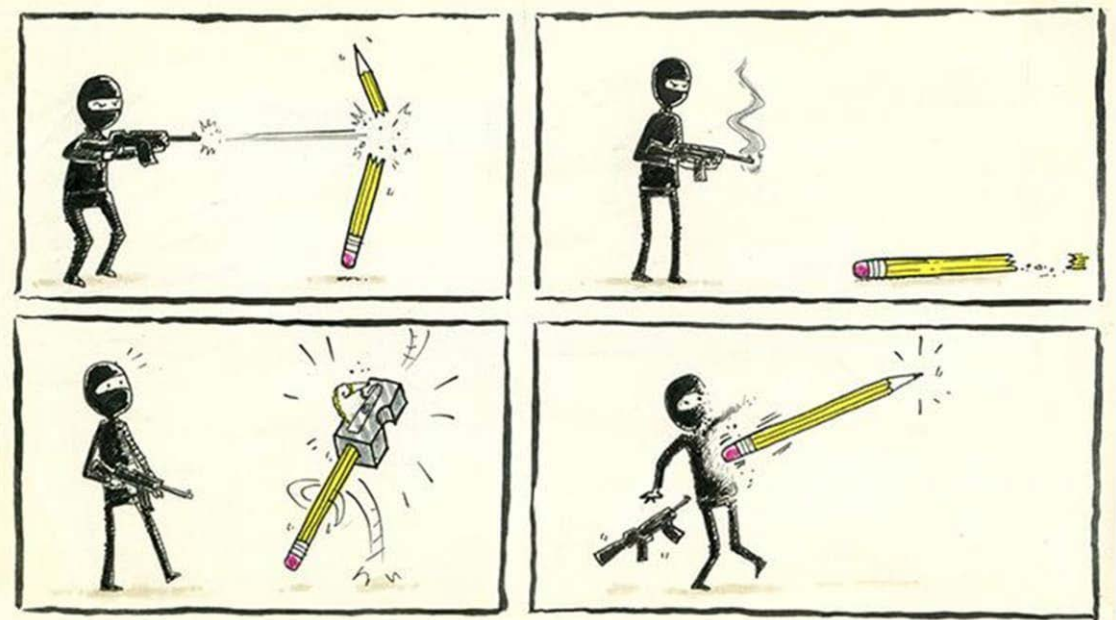

JE SUIS CHARLIE

Fuente: <https://twitter.com/RteeFufkin/status/552937192252006400>.

Una diferencia interesante con respecto a las imágenes anteriores es que aquí el lápiz (y también el sacapuntas) no necesita de la mediación de lo humano (la mano del dibujante) para desarrollar su acción, sino que, dentro del marco comunicativo especial abierto por el humor gráfico (en el que caben procedimientos como el ingenio, el juego o la ficción), es capaz de cobrar vida propia, actuar por sí mismo y combatir la amenaza terrorista de forma activa.

En esta otra imagen (figura 6), obra del dibujante holandés Ruben L. Oppenheimer, se hace un uso diferente de los lápices, no ya como objetos de acción en la lucha contra el terrorismo, sino como elementos arquitectónicos estáticos similares a dos torres. En la imagen vemos también cómo un avión negro se dirige hacia los dos lápices torres y está a punto de chocar contra el primero de ellos. La imagen de Oppenheimer es una ingeniosa y sobria manera de referirse a los atentados del 11 de septiembre de 2001 o, dicho de otra forma, de entender el atentado a Charlie Hebdo a partir de otro ataque terrorista y de una de sus imágenes más icónicas: la del avión acercándose a las emblemáticas torres gemelas de la ciudad de Nueva York.

Vemos aquí un uso ejemplar de la metáfora visual, entendiendo que la esencia de la metáfora es, según la famosa definición de Lakoff y Johnson (1995: 41), «entender y experimentar una cosa en términos de otra». La 
metáfora supone el uso de una palabra por otra palabra, de un signo por otro signo, y expresa algo novedoso o no muy familiar a partir de un signo mucho más conocido y familiar. Para ello se recurre «al repertorio del lenguaje usadero», donde, como decía Ortega y Gasset:

[...] cada voz se encuentra ya adscrita a una significación. A fin de hacerse entender, elige la palabra cuyo usual sentido tenga alguna semejanza con la nueva significación. De esta manera, el término adquiere la nueva significación a través y por medio de la antigua, sin abandonarla. Esto es la metáfora. (Ortega y Gasset, 1957: 388)

Para Jonathan Culler, la metáfora es básicamente «una versión más de un modo primordial de conocimiento: conocemos algo viéndolo como otra cosa» (Culler, 2000: 89), entendemos un signo viéndolo como otro signo. Por eso, la metáfora es, como ha señalado Peñamarín (1997: 125), una «estrategia discursiva privilegiada en el humor gráfico", pues "permite a la imagen, con o sin palabras, referirse al mundo conocido por los interlocutores y comentarlo figurada e indirectamente desde otros sistemas de representación».

Figura 6. Charlie Hebdo, de Ruben L. Oppenheimer

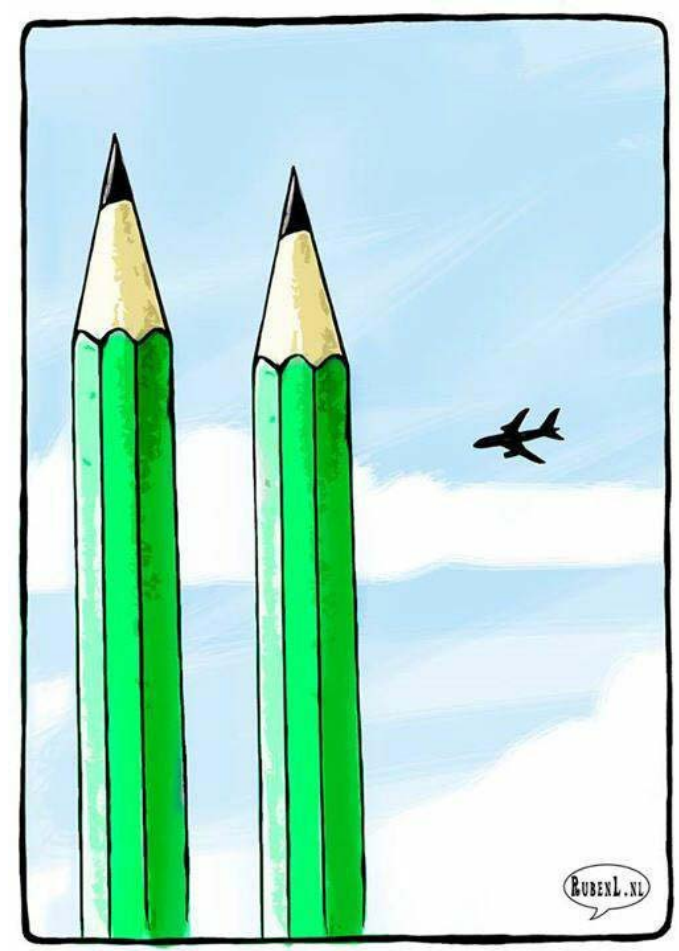

Fuente: <https://twitter.com/RLOppenheimer/status/552848047089405952/photo/1>. 
En esta imagen, los dos lápices erguidos y el avión acercándose a ellos sirven para que entendamos el ataque terrorista contra Charlie Hebdo en términos de otro famoso ataque terrorista y para denunciar, por tanto, los actos del 7 de enero de 2015 activando en nuestra mente los ataques del 11 de septiembre de 2011. Si, como demostraron Lakoff y Johnson (1995: 42), «los procesos del pensamiento humano son en gran medida metafóricos», no resulta extrańo que los dibujantes de humor gráfico recurran habitualmente a las metáforas para hacer comprensibles sus mensajes, pues, como señala Lakoff en otro lugar (2007: 44), las metáforas duermen en nuestro cerebro, en espera de que se las despierte y se las active para hacer comprensibles los nuevos fenómenos y experiencias a las que nos enfrentamos diariamente.

La poderosa metáfora visual que constituye esta viñeta puede entenderse como una "metáfora del terror» a través de la cual, citando de nuevo a Lakoff (2007: 45), «los horrores literales externos» se convierten «en horrores metafóricamente sentidos», de forma que ante la imagen de un avión dirigiéndose a unos edificios sentimos metafóricamente el horror de las personas que fallecieron en los ataques contra las torres gemelas de Nueva York, y ante la imagen de un avión dirigiéndose a unos lápices como los representados en la viñeta analizada, sentimos metafóricamente el horror literal de los dibujantes de Charlie Hebdo asesinados durante el ataque terrorista del 7 de enero de 2015.

\section{Más allá del lápiz}

Aunque un gran número de dibujantes recurrieron a la representación visual de lápices (y objetos similares como plumas o pinceles) como símbolos de la lucha por la libertad de expresión y como homenaje a las víctimas del atentado, algunos dibujantes recurrieron a otro tipo de imágenes para ejercer el mismo tipo de crítica, configurando un texto visual o verbovisual distinto a los analizados anteriormente. La siguiente imagen (figura 7), firmada por el dibujante italiano Enrico Bertuccioli (Ebert), representa un texto de estas características.

Aquí, las armas no son ya los lápices o sus extensiones metonímicas (plumas, pinceles, rotuladores, etc.), sino las mismas páginas de la revista Charlie Hebdo y, más concretamente, los polémicos números especiales y las caricaturas satíricas que desataron la ira de gran parte de la comunidad islámica. En la imagen, el terrorista (que actúa, de nuevo, como una metonimia del terrorismo) es interceptado por las páginas de estos números de la revista, que, juntas, forman una especie de collage verbovisual bajo el cual el terrorista queda sepultado y sin posibilidad de utilizar su arma. Si, como ha señalado Boczkowski (2006), a lo largo de la historia los lectores han encontrado para las páginas de periódicos y revistas todo tipo de usos no contemplados (por ejemplo, para envolver alimentos, equilibrar mesas inestables, cubrir alfombras, avivar el fuego y dar calor al cuerpo, etc.), el dibujante de esta vińeta imagina un nuevo uso como arma arrojadiza capaz de desestabilizar y neutra- 
lizar los movimientos del terrorista. La viñeta funciona, así, como una defensa de la libertad de expresión y del trabajo gráfico realizado por Charlie Hebdo en estos polémicos números, sumándose así al tipo de narrativa solidaria desplegada por el resto de textos analizados en este artículo.

Figura 7. Charlie Hebdo!, de Ebert

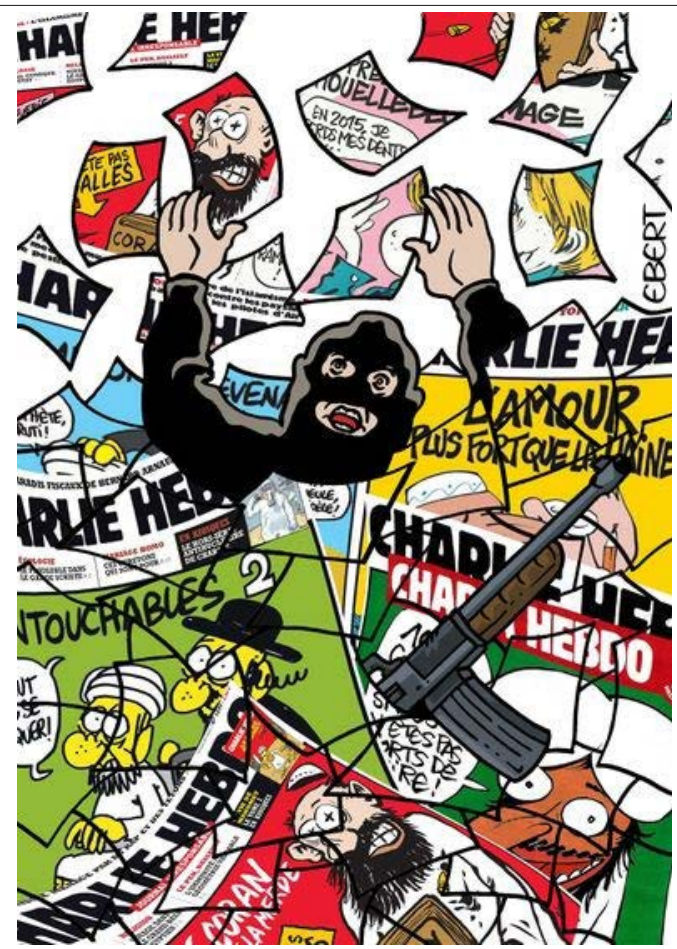

Fuente: <https://www.cartoonmovement.com/cartoon/18700>.

\section{Conclusiones}

A lo largo del presente texto hemos analizado cómo los dibujantes y humoristas gráficos de distintos países occidentales reaccionaron ante el atentado contra el semanario satírico francés Charlie Hebdo que causó la muerte de varias personas, entre ellos cinco dibujantes de la revista. En general, el discurso elaborado por los humoristas gráficos en sus viñetas y tiras cómicas fue un discurso de solidaridad con las víctimas del atentado, de condena del terrorismo y su violencia y de defensa de la libertad de expresión. Este discurso verbovisual es coherente con las narrativas periodísticas generadas por los principales medios de comunicación occidentales (Wolska-Zogata, 2015; Gómez-Domínguez et al., 2017), que condenaron el acto terrorista y convirtieron a Charlie Hebdo en un símbolo de la lucha por la libertad de expresión, 
preservando así la mitología oficial y revirtiendo los efectos de la comunicación terrorista violenta (Petrof, 2015).

Sin embargo, como hemos podido comprobar a partir de las imágenes analizadas, el peculiar lenguaje verbovisual del humor gráfico y la imaginación y la creatividad que lo caracteriza, introduce una novedad interesante con respecto a estas narrativas: el protagonismo del lápiz como arma en la lucha terrorista y símbolo de la libertad de expresión y los valores democráticos. Salvo algunas excepciones, como la última viñeta analizada, la mayoría de dibujantes y humoristas gráficos encontraron en la imagen del lápiz (y objetos parecidos como pinceles o plumas) una ingeniosa y creativa manera de defender su trabajo y rendir homenaje a los compañeros muertos durante el atentado. En este sentido, el discurso visual y verbovisual articulado por estos dibujantes en sus vińetas o tiras cómicas puede interpretarse como un metadiscurso humoristico, entendido como un discurso que hace referencia y reflexiona sobre el humor gráfico a partir del propio humor gráfico y algunos de sus signos más característicos, como el lápiz en este caso, herramienta fundamental de trabajo en la elaboración de este tipo de textos mediáticos.

En definitiva, para los dibujantes y humoristas gráficos, el atentado terrorista contra Charlie Hebdo no fue solo un ataque a una revista satírica y a unos compańeros de trabajo, sino un ataque directo al humor gráfico y a todo lo que este representa: imaginación, creatividad, juego, ironía, transgresión, burla, seriedad, sarcasmo, parodia, libertad...

\section{Referencias bibliográficas}

ABRIL, G. (2008). Análisis crítico de textos visuales. Mirar lo que nos mira. Madrid: Síntesis.

AL NASHMI, E. (2018). «From selfies to media events: How Instagram users interrupted their routines after the Charlie Hebdo shootings». Digital Journalism, 6 (1), 98-117.

<https://doi.org/10.1080/21670811.2017.1306787>

ÁLVAREZ JUNCO, M. (2016). El humor gráfico y su mecanismo transgresor. Madrid: A. Machado Libros.

BARTHES, R. (1986). Lo obvio y lo obtuso: Imágenes, gestos, voces. Barcelona: Paidós.

BEZANSON, M. E. (2017). «Political cartoons as epideictic: Rhetorical analysis of two of the Charlie Hebdo political cartoons». First Amendment Studies, 51 (1), 1-13. $<$ https://doi.org/10.1080/21689725.2017.1301264>

BOCZKOWSKI, P. J. (2006). Digitalizar las noticias: Innovación en los diarios online. Buenos Aires: Manantial.

Bouko, C.; CAlabrese, L. y De ClercQ, O. (2016). «Cartoons as interdiscourse: A quali-quantitative analysis of social representations based on collective imagination in cartoons produced after the Charlie Hebdo attack». Discourse, Context \& Media, 15, 24-33. <https://doi.org/10.1016/j.dcm.2016.12.001>

CUlLER, J. (2000). Breve introducción a la teoría literaria. Barcelona: Crítica. 
Domínguez, M. (2015). "On the Origin of Metaphors». Metaphor and Symbol, 30 (3), 240-255. <https://doi.org/10.1080/10926488.2015.1049858>

EKO, L. y HellmUeller, L. (2018). «To republish or not to republish: The "Je Suis Charlie" Mohammed cartoon and journalistic paradigms in a global context». International Communication Gazette, 80 (3), 207-229. $<$ https://doi.org/10.1177/1748048517727220>

GASCA, L. y GUBERN, R. (1991). El discurso del cómic. Madrid: Cátedra.

GiaXoglou, K. (2018). «\#JeSuisCharlie?: Hashtags as narrative resources in contexts of ecstatic sharing». Discourse, Context \& Media, 22, 13-20. <https://doi.org/10.1016/j.dcm.2017.07.006>

Gómez-Domínguez, P.; Candelaria Rivera, G.; Pérez latorre, O. y GÓmEZ-PUERTAS, L. (2017). «Las narrativas del ataque contra Charlie Hebdo: Un estudio de la cobertura periodística internacional». Estudios sobre el Mensaje Periodistico, 23 (1), 417-436. $<$ https://doi.org/10.5209/ESMP.55605>

GreImAS, A. J. (1976). Maupassant: La sémiotique du texte: exercises pratiques. París: Seuil.

Gustafson, K. L. y KenIX, L. J. (2017). «Visually Framing Press Freedom and Responsibility of a Massacre: Photographic and Graphic Images in Charlie Hebdo's Newspaper Front Pages around the World». Visual Communication Quarterly, 23 (3), 147-160. <https://doi.org/10.1080/15551393.2016.1190623>

JENKINS, J. y TANDOC, E. C. (2019). «Journalism under attack: The Charlie Hebdo covers and reconsiderations of journalistic norms». Journalism, 20 (9), 11651182 . <https://doi.org/10.1177/1464884917724597>

LAKOFF, G. (2007). No pienses en un elefante: Lenguaje y debate politico. Madrid: Editorial Complutense.

LAKOFF, G. y JOHnSOn, M. (1995). Metáforas de la vida cotidiana. Madrid: Cátedra.

LEONE, M. (2015). "To be or not to be Charlie Hebdo: Ritual patterns of opinion formation in the social networks». Social Semiotics, 25 (5), 656-680. <https://doi.org/10.1080/10350330.2015.1080038>

JOHANSSON, M. y LAIPPALA, V. (2020). «Affectivity in the \#jesuisCharlie Twitter discusión». Pragmatics, 30 (2), 179-200. $<$ https://doi.org/10.1075/prag.18066.joh>

Lozano, J.; Peña-Marín, C. y Abril, G. (1982). Análisis del discurso: Hacia una semiótica de la interacción textual. Madrid: Cátedra.

Magariños de Morentín, J. A. (2008). La semiótica de los bordes: Apuntes de metodología semiótica. Córdoba: Comunicarte.

Mitchell, W. J. T. (1994). Picture Theory: Essays on Verbal and Visual Representation. Chicago: University of Chicago Press.

NiEmEYER, K. (2019). "The front page as a time freezer: An analysis of the international newspaper coverage after the Charlie Hebdo attacks». Media, War \& Conflict, 12 (2), 187-201. <https://doi.org/10.1177/1750635219839378>

Ortega y Gasset, J. (1957). Obras Completas. Vol. 2. Madrid: Revista de Occidente. 
PAYNE, R. (2018). "Je suis Charlie”: Viral circulation and the ambivalence of affective citizenship». International Journal of Cultural Studies, 21 (3), 277-292. <https://doi.org/10.1177/1367877916675193>

PeŃAMARín, C. (1996). «El humor gráfico y la metáfora polémica». La Balsa de La Medusa, 38-39, 107-132.

- (1997). "La imagen dice no: Metáfora e índice en el lenguaje del humor gráfico». La Balsa de la Medusa, 41-42, 91-128.

PETROF, S. (2015). «The dialectics of media representation: "Je Suis Charlie" as fetishization of an image». ESSACHESS: Journal for Communication Studies, 8 (2), 207-225.

ROSE, G. (2001). Visual Methodologies: An Introduction to the Interpretation of Visual Materials. Londres: Sage.

Sousa SANTOS, B. de (2015). "Charlie Hebdo: una reflexión difícil». Público. Recuperado de <https://blogs.publico.es/espejos-extranos/2015/01/13/charlie-hebdouna-reflexion-dificil/> [Fecha de consulta: 01/10/2019].

WolsKa-ZogatA, I. (2015). "The Story of Charlie Hebdo: An Analysis of European and American Newspapers». Mediterranean Journal of Social Sciences, 6 (2), 353362.

<https://doi.org/10.5901/mjss.2015.v6n2s5p353> 